\title{
GARAGEM DO PET - A IMPORTÂNCIA DE CONHECIMENTOS PRÁTICOS NA FORMAÇÃO DO ESTUDANTE DE ENGENHARIA ELÉTRICA
}

\author{
Ruan Carlos Virginio dos Santos - ruan.santos@ cear.ufpb.br \\ Vitor de Sousa França - vitor.franca@ cear.ufpb.br \\ Gabriela Barbosa Guedes Pereira - gabriela.pereira@cear.ufpb.br \\ Gabriela de Moura T. U. C. Rolim-gabriela.cavalcanti@cear.ufpb.br \\ Nady Rocha - nadyrocha@ cear.ufpb.br \\ Universidade Federal da Paraíba \\ Cidade Universitária, s/n - Castelo Branco III \\ 58051085 - João Pessoa - Paraíba
}

\begin{abstract}
Resumo: Este artigo tem como objetivo descrever a atividade desenvolvida pelo Programa de Educação Tutorial em Engenharia Elétrica da Universidade Federal da Paraíba (PETElétrica/UFPB), denominada Garagem do PET, que até a sua nona edição já contribuiu na formação de mais de 135 alunos dos cursos de graduação em Engenharia Elétrica e Engenharia de Energias Renováveis. A Garagem do PET utiliza da interdisciplinaridade para ensinar, a partir de uma metodologia ativa, todas as etapas para a confecção de placas de circuito impresso, permitindo assim, o engajamento dos calouros em atividades práticas. Além disso, proporciona uma formação complementar aos estudantes, uma vez que as ferramentas utilizadas no minicurso não são ensinadas durante a graduação. Além da descrição de todas as etapas do minicurso Garagem do PET, neste artigo são apresentados e discutidos os dados obtidos a partir de uma pesquisa realizada com os alunos. Os resultados mostram que $81 \%$ dos entrevistados afirmam que o minicurso contribuiu de maneira positiva na sua formação.
\end{abstract}

Palavras-chave: Metodologia Ativa. Placa de Circuito Impresso. Formação Profissional.

\section{INTRODUÇÃO}

As intensas transformações do mundo moderno impõem uma série de desafios aos profissionais da atualidade. Cada vez mais, o mercado de trabalho necessita que esses sejam facilmente adaptáveis a diferentes realidades e capazes de se reinventar e de propor soluções para demandas constantes e diversas.

Neste cenário, os modelos educacionais são colocados em questão, pois como aponta Hoehnke, Koch e Lutz (2005), os métodos tradicionais de ensino conduzem a uma negligência das capacidades criativas individuais em detrimento de competências que são puramente mecânicas e repetitivas, ou seja, são menos capazes de criar profissionais suficientemente capacitados para a nova realidade.

De acordo com Ribeiro e Mizukami (2004), os objetivos dos cursos de graduação em engenharia são objeto de estudo de diversos pesquisadores. A partir de várias dessas pesquisas, percebe-se que o ensino de engenharia deve ser direcionado para o desenvolvimento simultâneo de conhecimentos, habilidades e atitudes. Portanto, pode-se 
então citar como alguns dos principais atributos profissionais esperados de engenheiros (RIBEIRO E MIZUKAMI, 2004):

a) conhecimentos: ciência e tecnologia, computação, administração, impactos ambientais e sociais da tecnologia etc.;

b) habilidades: desenvolvimento de projetos, solução de problemas, comunicação, trabalho em equipe, auto-avaliação, avaliação de pares etc.; e

c) atitudes: ética, responsabilidade para com colegas, sociedade e profissão, iniciativa, flexibilidade, empreendedorismo, motivação para o aprendizado autônomo ao longo da vida, dentre outras.

Diante dessas necessidades, em 2019, o Ministério da Educação (MEC) publicou as novas Diretrizes Curriculares Nacionais (DCNs) para os cursos de graduação em Engenharia, em busca de que os engenheiros em formação possam atender às futuras demandas da profissão. As principais mudanças das novas diretrizes são em relação a uma maior flexibilidade na constituição da grade curricular, com uma formação baseada em competências e maior foco no aprendizado prático.

Além de fundamental para o aprendizado e formação das habilidades e competências dos estudantes, as diretrizes também citam que as atividades práticas são de grande importância para combater a evasão dos cursos, como exemplificado no trecho abaixo extraído das novas DCNs (MINISTÉRIO DA EDUCAÇÃO, 2019):

O ponto principal é imprimir maior sentido, dinamismo e autonomia ao processo de aprendizagem em Engenharia por meio do engajamento do aluno em atividades práticas, desde o primeiro ano do curso. Assim, o aprendizado baseado em metodologias ativas, a solução dos problemas concretos em atividades, que exijam conhecimentos interdisciplinares, são alguns dos instrumentos que podem ser acionados para elevar a melhoria do ensino e para combater a evasão escolar.

Ainda, segundo Silva Filho (2007), a evasão escolar no ensino superior é um grave problema para o sistema educacional brasileiro. Esse fato é reforçado pelo parecer da comissão do Conselho Nacional de Educação (CNE) que apresenta o dado de que há cerca de $50 \%$ de evasão nos cursos de Engenharia.

Como apontam Dias, Novikoff e Souza (2011), o ensino desvinculado da prática provoca a desmotivação dos estudantes. Portanto, com o objetivo de atenuar a grande taxa de evasão verificada em todas as engenharias, as novas DCNs preveem a implementação de políticas de acolhimento como, por exemplo, a realização de cursos extracurriculares. Segundo o Projeto de Resolução que institui as DCNs, Capítulo III e Art. 7, os sistemas de acolhimento previstos devem considerar (MINISTÉRIO DA EDUCAÇÃO, 2019):

I - as necessidades de conhecimentos básicos que são pré-requisitos para o ingresso nas atividades do curso de graduação em Engenharia;

II - a preparação pedagógica e psicopedagógica para o acompanhamento das atividades do curso de graduação em Engenharia; e

III - a orientação para o ingressante, visando melhorar as suas condições de permanência no ambiente da educação superior. 
Nesse contexto, o grupo PET-Elétrica da Universidade Federal da Paraíba (UFPB) promove atividades que reforçam o sentido prático da engenharia e a habilidade do aluno de investigação de problemas e soluções.

Neste artigo, será apresentado o minicurso Garagem do PET, uma oficina de confecção de placas de circuito impresso (PCIs) destinada aos ingressantes dos cursos de Engenharia Elétrica e Engenharia de Energias Renováveis da UFPB. O minicurso, que se encontra em sua $9^{\text {a }}$ (nona) edição e já atingiu um total de 135 estudantes, possui como finalidade atenuar as dificuldades enfrentadas por esses ao se depararem com a necessidade da confecção de uma PCI e, junto a isso, promover aos ingressantes um espaço de aproximação e acolhimento. No mais, será discutido ao fim do artigo os resultados de duas pesquisas de satisfação, uma realizada com os participantes ao fim do minicurso, com foco em avaliar sua qualidade metodológica, e outra realizada com estudantes de diferentes períodos dos cursos, de forma a averiguar a utilidade dos conhecimentos abordados nos minicursos ao decorrer da graduação.

\section{FUNDAMENTAÇÃO TEÓRICA}

Cabral et al. (2019) enfatiza que no curso de Engenharia Elétrica da Universidade Federal da Paraíba (UFPB) existem disciplinas que necessitam de experimentos para que se obtenha uma melhor compreensão do conteúdo. Porém, é perceptível que no decorrer dessas aulas os estudantes se deparam com algumas barreiras referentes a conhecimentos práticos básicos e fundamentais aos quais não foram anteriormente apresentados.

A partir de uma pesquisa realizada pelo grupo PET, com 41 estudantes dos cursos de graduação em Engenharia Elétrica e Engenharia de Energias Renováveis, constatou-se que 80\% dos estudantes não tiveram contato com placas de circuito impresso antes da graduação. Essas placas são utilizadas para fixar e conectar eletricamente componentes eletrônicos (COSTA PINTO; LOLIS; OTANI, 2012). Junto a isso, uma grande inquietação é que 68,3\% dos graduandos já precisaram fazer uma PCI em algum projeto ou disciplina durante o curso, o que enfatiza a importância desse conhecimento na formação complementar dos estudantes.

Além disso, PCIs são de grande importância na construção de projetos, dado que permitem uma melhor organização dos componentes e segurança na hora de manuseio, evitando falhas como curtos-circuitos e ruídos eletrônicos, advindos da má conexão entre os componentes. Nesse contexto, foi criado o minicurso Garagem do PET, que é realizado semestralmente durante a Recepção Solidária, evento organizado pelo grupo PET-Elétrica com intuito de receber os ingressantes nos cursos de graduação em Engenharia Elétrica e Engenharia de Energias Renováveis da UFPB.

A intenção do minicurso é suprir uma necessidade percebida pelo grupo PET em relação a conhecimentos e habilidades práticas específicas, necessárias para os estudantes da graduação. Dessa forma, a aula foi estruturada para apresentar ao calouro alguns conhecimentos básicos sobre a produção de uma PCI, ensinando-os a transformar um circuito elétrico em uma PCI funcional, com detalhamento de cada etapa do processo, desde as etapas conceituais até a finalização e teste do circuito.

Dependendo das especificações do projeto, as PCIs podem ser fabricadas principalmente em fenolite, fibra de vidro ou politetrafluoretileno (PTFE), materiais isolantes com diferentes características para aplicações distintas, sejam mais corriqueiras ou específicas, como por exemplo a necessidade de uma maior resistência a impactos ou a de suportar tensões alternadas de alta frequência (MEHL, 2011). Já para realizar a condução nas placas, é majoritariamente utilizado o cobre, devido a suas boas propriedades: elétrica, que oferece uma boa condutividade; e mecânica, que permite a confecção de camadas pouco espessas. 
Para a fabricação das PCIs existem processos aditivos e subtrativos. O primeiro, geralmente de custo elevado e utilizado em indústrias, consiste em depositar material condutor sobre a placa. Já no segundo, ocorre a corrosão do material condutor já existente na camada isolante (PELZER, 2013). Dentre os processos subtrativos, pode-se citar a confecção por fresamento ou por corrosão, no qual o circuito pode ser transferido para a placa pelo método térmico ou por maneiras mais artesanais utilizando canetas permanentes.

O fresamento é feito a partir de um equipamento de corte chamado fresa, o qual é capaz de remover o material condutor da placa de maneira precisa realizando movimentos rotativos contínuos (LEAL; RIBAS, 2015). Enquanto isso, o método térmico consiste em transferir para a PCI a trilha impressa em um papel, normalmente fotográfico, através do aquecimento deste, seja utilizando um ferro de passar, uma plastificadora ou outro equipamento mais especializado. Por fim, as placas podem ser confeccionadas também desenhando o circuito, à mão, com caneta permanente, que impedirá que as partes sob a tinta sejam corroídas.

Neste trabalho, foi escolhido para a oficina de produção das PCIs o fenolite, um laminado industrial que funciona como isolante elétrico, revestido por uma fina camada de cobre que servirá como a trilha condutora nos circuitos que serão impressos na placa. Quanto ao método de fabricação utilizado, optou-se pela confecção com caneta permanente devido à simplicidade, praticidade e baixo custo.

\section{ESTRUTURA DO MINICURSO}

O minicurso Garagem do PET possui atualmente uma carga horária de quatro horas, das quais as duas primeiras possuem caráter teórico e são realizadas dentro de uma sala de aula, como pode ser visto na Figura 1. Nesta primeira parte é apresentado aos alunos a história do surgimento das placas de circuito impresso e de sua importância nos dispositivos eletrônicos presentes em seus cotidianos. Ademais, é discutido com os participantes as possíveis aplicações de PCIs dentro dos cursos de graduação em Engenharia Elétrica e Engenharia de Energias Renováveis, com relatos pessoais dos integrantes do grupo PET sobre suas experiências na confecção de placas de circuito impresso durante sua formação.

Figura 1 - Fotografia da aula teórica do minicurso Garagem do PET no período 2019.1.

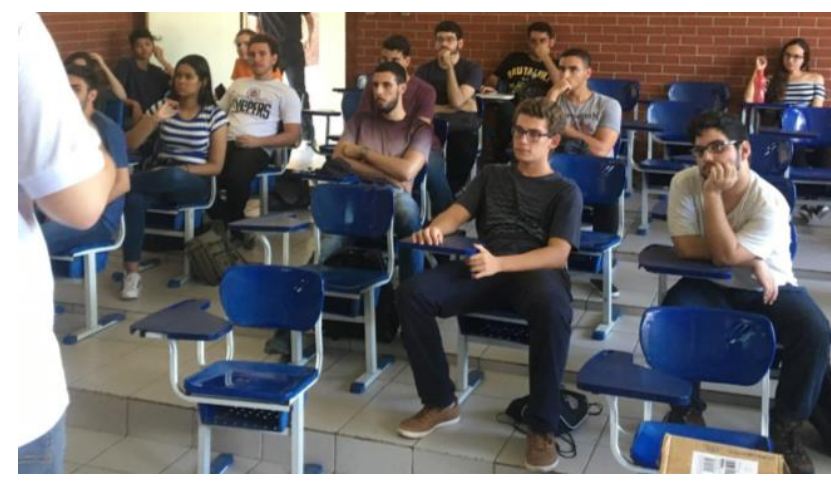

Fonte: Acervo dos autores, 2019.

A primeira etapa do minicurso se atém em descrever algumas das possíveis formas de se construir uma placa de circuito impresso, detalhando os processos utilizados e as ferramentas necessárias para a confecção das PCIs. Outrossim, também são apresentados diversos softwares para a elaboração de projetos de circuitos, que facilitam a concepção do leiaute do 
circuito e suas adaptações para PCIs. Tais softwares são essenciais para a construção de projetos eletrônicos mais complexos.

Ainda na parte teórica, são ensinados conceitos de eletrônica básica e o funcionamento dos componentes eletrônicos que serão utilizados para a construção da PCI durante o minicurso. A placa utilizada constitui-se de um circuito elétrico simples composto por um LED (Light-Emitting Diode) e um resistor. Durante o minicurso é utilizada, como fonte de alimentação, uma fonte de corrente contínua de $5 \mathrm{~V}$, mas que pode ser substituída por um suporte de duas a quatro pilhas, de acordo com a intensidade de brilho do $L E D$ desejada.

Dentro das diversas formas apresentadas de se confeccionar uma placa de circuito impresso, foi escolhido o método mais simples e de menor custo. Esse método consiste na utilização de um pincel marcador permanente para desenhar o circuito elétrico em uma placa de fenolite e é comumente utilizado para a confecção de circuitos simples, que não demandam de muitos detalhes em sua elaboração.

Os materiais necessários para a construção da PCI foram:

- Pincel marcador permanente;

- Palha de aço;

- Placa de fenolite;

- Percloreto de ferro;

- Furador manual para Placa de Circuito Impresso;

- Componentes eletrônicos: Resistor e LED.

O primeiro passo na construção da PCI é polir com uma palha de aço a camada de cobre na placa de fenolite até que fique com um brilho evidente. Dessa forma, o cobre ficará limpo e livre de oxidação, o que poderia dificultar a fixação do circuito desenhado com o marcador permanente.

A Figura 2 mostra o diagrama esquemático de como se deve desenhar sobre o cobre o circuito citado anteriormente. Os círculos e quadrados, também conhecidos como ilhas de cobre, representam os pontos onde serão encaixados os terminais dos componentes, indicando também onde a placa será perfurada. Essas ilhas de cobre são também o ponto onde será realizada a solda do componente na placa. As linhas representam as trilhas de cobre que permitirão a passagem de corrente elétrica entre cada componente.

Após desenhado o circuito conforme indicado, a placa é então levada para o processo de corrosão do cobre, imergindo-a em uma solução aquosa de percloreto de ferro. Por se tratar de um composto químico tóxico, a fim de evitar sua inalação, a parte prática do minicurso é realizada ao ar livre em um ambiente ventilado. Durante essa etapa, todos os cuidados de manuseio e descarte da solução utilizada são tomados e ensinados. Após a corrosão, apenas o cobre demarcado, correspondente as trilhas condutoras de corrente elétrica, permanece na placa de fenolite. Então, as placas são lavadas e secadas para que todo o percloreto de ferro seja removido de sua superfície.

Figura 2 - Esquemático do circuito na PCI.

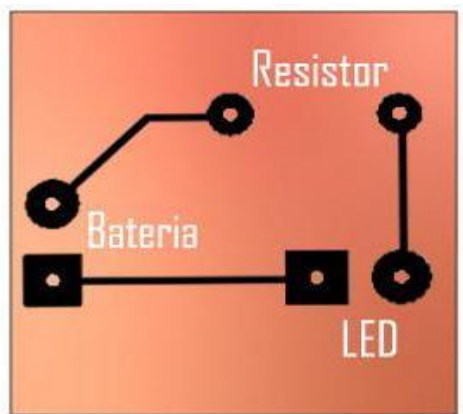

Fonte: Autoria própria, 2020. 
Para inserção dos componentes eletrônicos, utiliza-se um perfurador de placa de circuito impresso para fazer os furos onde os componentes serão encaixados. Após essa etapa, é ensinado como manusear o ferro de solda de modo seguro e como se deve soldar os terminais de cada um dos componentes de forma correta. Algumas etapas de todo o processo, assim como o resultado final da PCI, podem ser vistas na Figura 3.

Figura 3 - Etapas da confecção da placa de circuito impresso: (a) Polimento. (b) Corrosão. (c) Componentes soldados na placa.

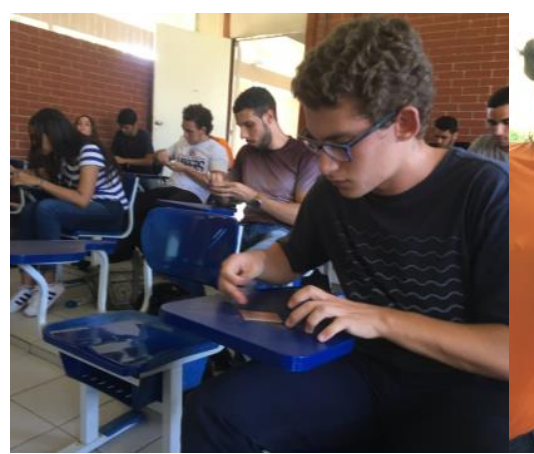

(a)

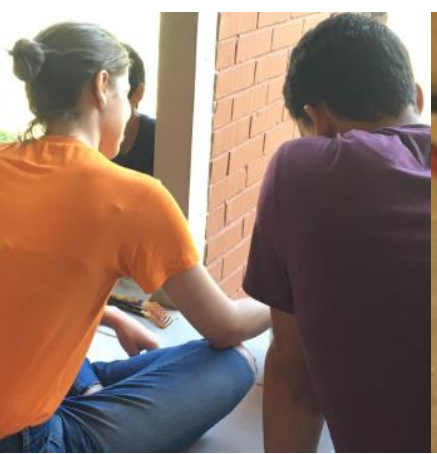

(b)

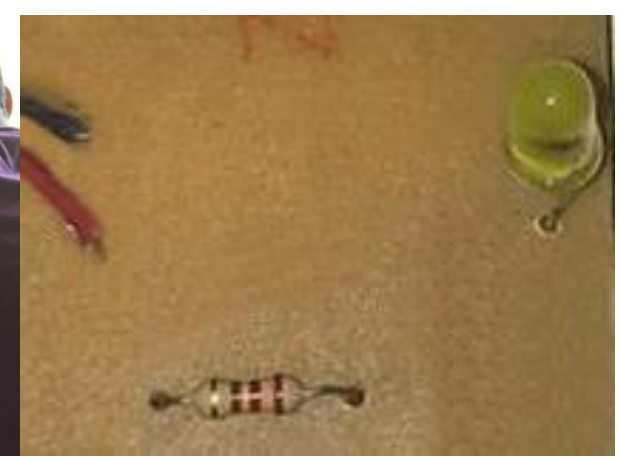

(c)

Fonte: Acervo dos autores, 2019.

\section{RESULTADOS E DISCUSSÕES}

Nos últimos quatro anos foram realizadas 9 (nove) edições da Garagem do PET, com a participação de 135 alunos de graduação. Nas últimas duas edições, realizadas em 2019, a Garagem contou com a participação de 39 estudantes, conforme apresentado na Figura 4. Com base nos resultados apresentados, ainda na Figura 4, é evidente que o número de alunos interessados pelo minicurso vem crescendo anualmente. Observa-se também que, em 2018, houve o engajamento de mais de 50 alunos de graduação. Contudo, esse número inflado ocorreu devido a 2018 ter sido um ano atípico que contou com 3 períodos letivos, medida tomada para atenuar os atrasos no calendário da universidade, o que aumentou o número de edições do minicurso ofertado anualmente.

Com o intuito de melhorar ainda mais a qualidade do minicurso oferecido pelo PET na formação complementar dos alunos da graduação, foi utilizado um formulário com várias perguntas direcionadas ao público alvo para avaliar as duas edições da Garagem do PET realizados em 2019. Constatou-se que $100 \%$ dos participantes disseram que o minicurso correspondeu a suas expectativas. Junto a isso, $87 \%$ dos estudantes acreditam que ajudará no seu desenvolvimento acadêmico e ainda, $83 \%$ avaliaram a ação como ótima, uma vez que agrega atividades práticas na formação dos estudantes.

Ademais, foram feitas perguntas sobre o desempenho do ministrante e dos monitores, sendo os resultados obtidos majoritariamente positivos. Ao final, foi solicitado que os alunos escrevessem comentários sobre suas expectativas a respeito do minicurso e de melhorias que acham necessárias serem realizadas. A partir das respostas obtidas nos comentários dos estudantes, a cada período realizado, o grupo PET-Elétrica é capaz de ter uma resposta direta sobre possíveis maneiras de aperfeiçoar o minicurso em suas futuras edições.

Com o objetivo de avaliar a repercussão do minicurso Garagem do PET na formação dos estudantes de graduação nesses últimos 4 (quatro) anos, um novo formulário foi aplicado a todos os estudantes dos cursos de Engenharia Elétrica e de Engenharia de Energias Renováveis. Essa pesquisa teve a participação de 41 (quarenta e um) estudantes de diferentes períodos. Dos resultados obtidos, observou-se que 58,5\% dos estudantes já precisaram fazer 
uma PCI durante o curso de graduação e $81 \%$ dos participantes afirmaram que o conhecimento adquirido na Garagem do PET foi importante para a execução dessa atividade. Esses resultados mostram a relevância do minicurso Garagem do PET na formação complementar dos discentes de graduação.

Outro resultado relevante extraído dessa pesquisa foi que 95,2\% dos participantes do minicurso acreditam que seria importante a construção de uma nova etapa com o objetivo de se aprofundar no desenvolvimento de PCIs com ferramentas computacionais. Com isso, observa-se que a implementação de uma carga horária adicional para ensino da utilização de softwares como o $\mathrm{KiCad}$, um programa computacional de código aberto para concepção de leiautes para PCIs, possibilitaria uma evolução significativa na estrutura do minicurso, abrindo a discussão entre os organizadores sobre novas melhorias possíveis.

A partir desses resultados, nota-se que o minicurso Garagem do PET está em sintonia com as novas Diretrizes Curriculares Nacionais do Curso de Graduação em Engenharia, pois permite aos estudantes do primeiro período se engajarem em atividades práticas e a utilizarem conceitos simples de eletrônica e eletricidade, que não são explorados na grade curricular dos alunos do primeiro semestre. A Garagem do PET associa atividades teóricas e práticas contribuindo para a ampliação da visão dos estudantes com relação a interdisciplinaridade dos cursos de engenharia. Desta maneira, o minicurso auxilia na formação do estudante e na melhoria do ensino e torna-se um importante agente contra a evasão escolar.

Figura 4 - Gráfico com o quantitativo de participantes em cada ano.

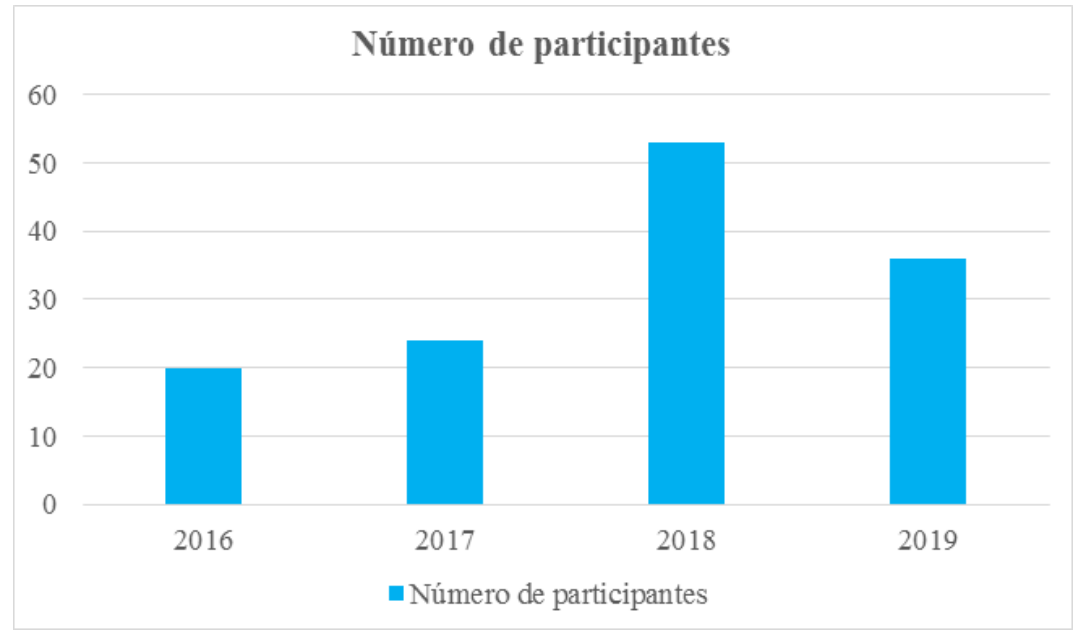

Fonte: Autoria própria, 2020.

\section{CONCLUSÕES}

Nesse artigo, apresentou-se o minicurso Garagem do PET, uma proposta do grupo PETElétrica da UFPB, que tem a finalidade de suprir a demanda dos alunos da graduação de Engenharia Elétrica e Engenharia de Energias Renováveis a respeito dos conhecimentos básicos necessários para confecção de placas de circuito impresso, visto que esses saberes são requisitados ao longo da graduação.

Junto a isso, foi visto como a Garagem se relaciona com as novas Diretrizes Nacionais Curriculares do Curso de Graduação em Engenharia, dado que essas apontam a necessidade da realização de cursos extracurriculares como instrumento de acolhimento que visam melhorar as condições de permanência no ambiente de ensino superior por meio do engajamento dos alunos em atividades práticas desde o início da graduação. 
Os resultados obtidos por meio dos formulários mostram que a atividade é responsável por despertar a motivação e o interesse dos ingressantes no curso ao terem um contato mais próximo com algo da área nos primeiros períodos, que normalmente possuem uma extensa carga teórica.

Além disso, tais resultados apontam a Garagem do PET como uma atividade efetiva no desenvolvimento de aptidões práticas úteis aos estudantes ao longo de sua graduação, como mostrado por mais de $80 \%$ dos alunos. Verificou-se também um elevado grau de satisfação, que pode ser creditado ao uso do projeto como forma de aprendizado de conceitos teóricos, garantindo um novo horizonte para criatividade a partir do conhecimento obtido.

Como perspectivas futuras, visando atender às requisições de 95,2\% dos alunos que responderam aos formulários e, dessa forma, melhorar os futuros índices de participação, estuda-se a possibilidade de introduzir softwares de concepção de circuitos integrados como, por exemplo, o KiCad. Além disso, a possível confecção de circuitos mais complexos, com outros componentes eletrônicos, e uma melhor divulgação do minicurso, para que seja notável aos ingressantes a importância do aprendizado que poderão obter.

Por fim, o projeto busca manter a associação entre teoria e prática para estimular a resolução de problemas e fazer com que essa estratégia, ao apresentar seus bons resultados, seja cada vez mais presente nos cursos de Engenharia Elétrica e Engenharia de Energias Renováveis, de forma a inserir profissionais cada vez mais capacitados no mercado de trabalho.

\section{REFERÊNCIAS}

CABRAL, A. P. C.; MORAES, E. da S.; BARBOSA, N. D. P.; PEREIRA, R. L. de A.; ROCHA, N. Fabricação de placas de circuito impresso como auxílio no ensino da engenharia elétrica. COBENGE 2019 XLVII - Congresso Brasileiro de Educação em Engenharia: Formação por competência na engenharia no contexto da globalização 4.0, Fortaleza-CearáBrasil, 17 set. 2019.

COSTA PINTO, A. C.; LOLIS, M. M.; OTANI, M. V. Z. Analisador de Placas de Circuito Impresso. 2012. 112 fls. Trabalho de Conclusão de Curso (Engenharia Industrial Elétrica Ênfase em Eletrônica e Telecomunicações) - Universidade Tecnológica Federal do Paraná. Curitiba, 2012.

DIAS, Â. M. M.; NOVIKOFF, C.; SOUZA, L. E. S. Laboratórios de aprendizagem de física: resultados de uma experiência pedagógica sustentável. Física na Escola, [s. l.], ano 2011, v. 12, n. 2, p. 12-14, outubro 2011.

HOEHNKE, K.; KOCH, V.; LUTZ, U. O Objectivismo na Filosofia e na Metodologia do Ensino. Lisboa, 2005. Disponível em: https://antoniogarcianeto.wordpress.com/2013/03/11/oobjetivismo-na-filosofia-e-na-metodologia-do-ensino/. Acesso em: 29 mai, 2020.

LEAL, J. F.; RIBAS, M. T. Fresadora CNC microcontrolada para confecção de placas de circuito impresso. 2015. 69f. Trabalho de Conclusão de Curso (Curso Superior de Tecnologia em Mecatrônica Industrial), Departamentos Acadêmicos de Eletrônica e Mecânica, Universidade Tecnológica Federal do Paraná. Curitiba, 2015. 
"Os desafios para formar hoje o engenheiro do amanhã"

MEHL, E. L. de M. Conceitos Fundamentais Sobre Placas de Circuito Impresso. 2011. Disponível em:

http://www.eletrica.ufpr.br/mehl/te232/textos/PCI_Conceitos_fundamentais.pdf. Acesso em: 25 jun, 2020.

MINISTÉRIO DA EDUCAÇÃO. Resolução CNE/CP Nº 2, DE 20 DE DEZEMBRO DE 2019. Diretrizes Curriculares Nacionais do Curso de Graduação em Engenharia. Disponível em: http://portal.mec.gov.br/. Acesso em: 28 mai, 2020

PELZER, E.. Confecção de Placas de Circuito Impresso por Processo Térmico. 2013.

RIBEIRO, L. R.; MIZUKAMI, M. da G. N. A PBL na Universidade de Newcastle: Um Modelo para o Ensino de Engenharia no Brasil?. Olhar de Professor, v. 7, n. 1, 3 fev. 2009.

SILVA FILHO, R.; MONTEJUNAS, P.; HIPÓLITO, O; LOBO, M. A Evasão no Ensino Superior Brasileiro. Cadernos de Pesquisa. v. 37, n 132, São Paulo, set/dez 2007.

\title{
THE PET GARAGE - THE IMPORTANCE OF PRACTICAL KNOWLEDGE IN THE PROFESSIONAL QUALIFICATION OF ELECTRICAL ENGINEERING STUDENTS
}

\begin{abstract}
This paper seeks to describe the activity developed by the Tutorial Education Program in Electrical Engineering at the Federal University of Paraíba (PET-Elétrica / UFPB), called PET Garage, which until its ninth edition has already contributed to the educational development of more than 135 undergraduate students in Electrical Engineering and Renewable Energy Engineering. The PET Garage is an interdisciplinary activity that teaches, from an active methodology, all the steps for the manufacture of printed circuit boards, thus allowing the engagement of freshman in practical activities. In addition, this activity provides complementary training for students, since the tools used in this course are not taught during the undergraduate program. Besides the description of all stages of the PET Garage course, this article presents and discusses the data obtained from a survey conducted with students. The results show that $81 \%$ of the interviewees claim that this activity contributed positively in their academic background.
\end{abstract}

Keywords: Active Methodology. Printed Circuit Board. Professional Qualification. 